Supporting Information for

\title{
Ionic Strength-Controlled Virtual Area of Mesoporous Platinum
}

Hankil Boo, ${ }^{\dagger}$ Sejin Park, ${ }^{\S}{ }^{\ddagger}$ Bonkyung Ku, ${ }^{\S}$ Yunmee Kim, ${ }^{\S}$ Jin Hyung Park, ${ }^{\ddagger}$ Hee-Chan $\mathrm{Kim}^{\ddagger *}$ and Taek Dong Chung ${ }^{\AA^{*}}$

${ }^{\dagger}$ ELBIO Corporation, 23 Ogeum-dong, Songpa-gu, Seoul 138-855, Korea,

${ }^{\ddagger}$ Department of Biomedical engineering, College of Medicine and Institute of Medical and Biological Engineering, Medical Research Center, Seoul National University, 28

Yongon-dong, Chongno-gu, Seoul 110-744, Korea,

and ${ }^{\S}$ Department of Chemistry, Sungshin Women's University, 249-1 Dongsun-dong,

Sungbuk-gu, Seoul 136-742, Korea 


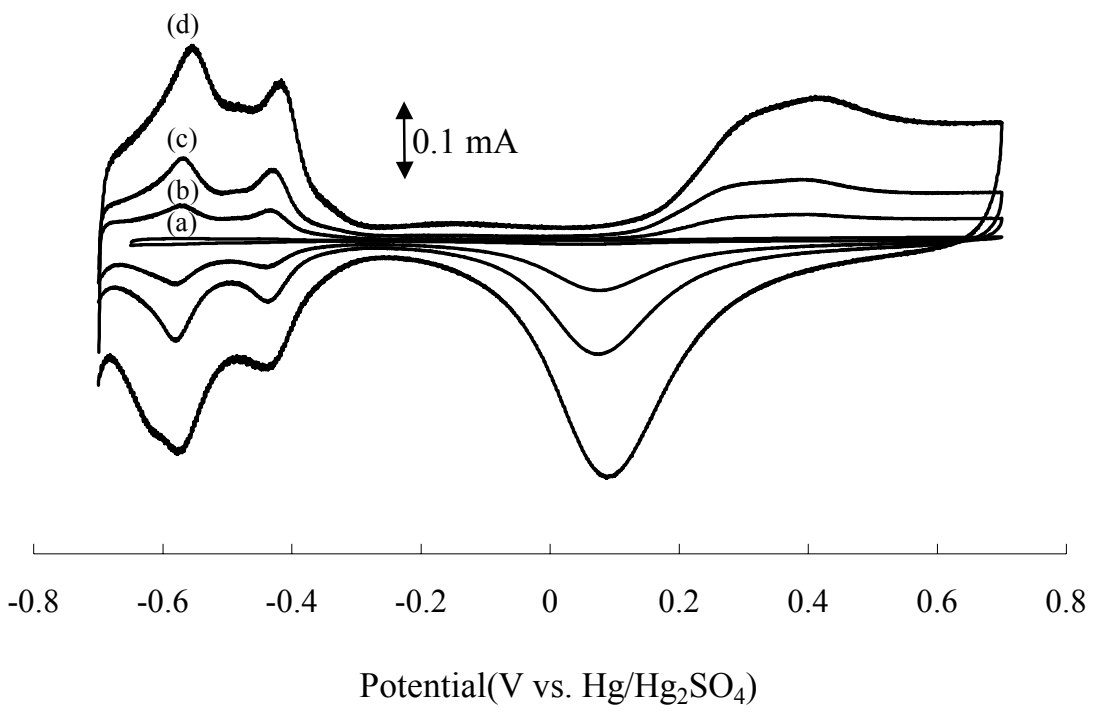

Figure 1. Cyclic voltammograms of Pt electrodes in $1 \mathrm{M} \mathrm{H}_{2} \mathrm{SO}_{4}$ aqueous solution. Scan rate: $200 \mathrm{mV} / \mathrm{s}$. The charge passed for Pt deposition and roughness factor are (a) 0 $\mathrm{mC}$ and 2.37, (b) $5 \mathrm{mC}$ and 29.1, (c) $10 \mathrm{mC}$ and 65.1 (d) $25 \mathrm{mC}$ and 158, respectively. The geometric areas of the flat and mesoporous Pt electrodes are $3.14 \times 10^{-2} \mathrm{~cm}^{2}$ and $7.85 \times 10^{-3} \mathrm{~cm}^{2}$, respectively.

Comment: Deposition of Pt was carried out at Pt disk electrodes that have the radius of $0.5 \mathrm{~mm}$ in the liquid crystalline mixture of hydrogen hexachloroplatinate hydrate(Aldrich), water, and octaethylene glycol monohexadecyl ether(Fluka) (29:29:42 in weight). The cyclic voltammograms of the flat and mesoporous Pt electrodes show the typical redox behavior of platinum itself and the adsorption and desorption of hydrogen in $\mathrm{H}_{2} \mathrm{SO}_{4}$ solution. 


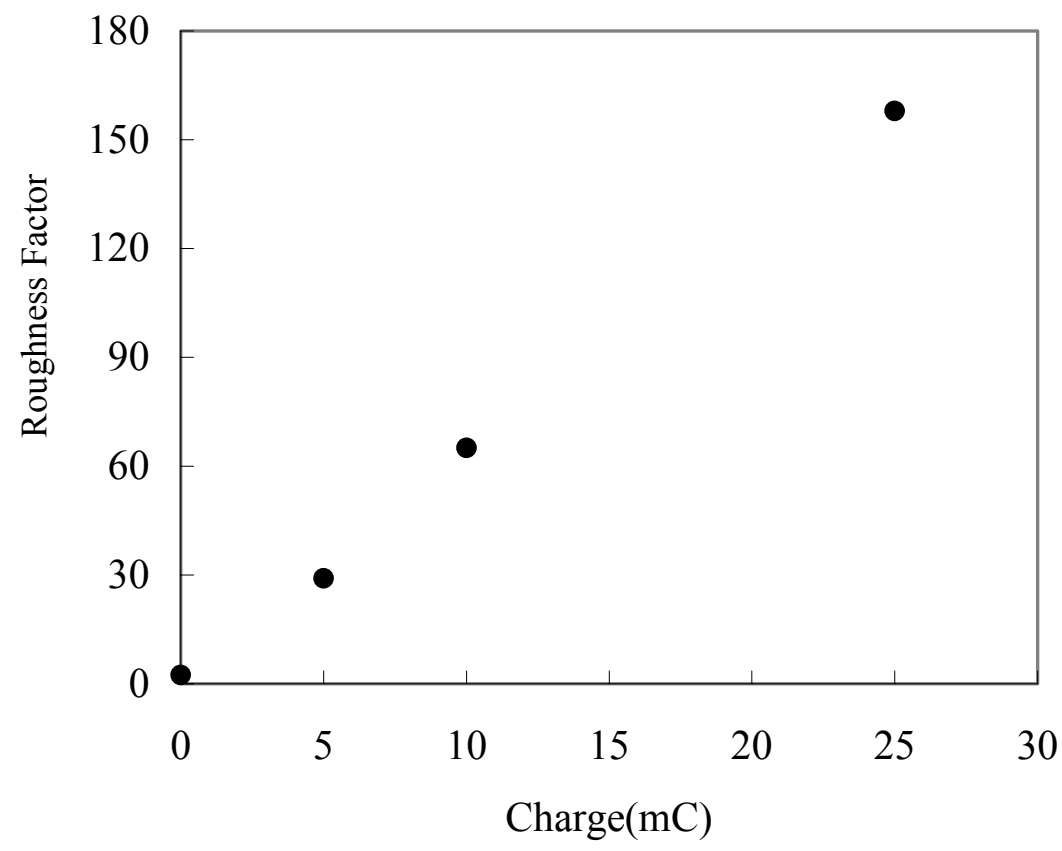

Figure 2. Plot of roughness factor vs. charge passed for Pt deposition.

Comment: From the peak area of hydrogen adsorption, roughness factor of the electrodes were calculated with the fact that a monolayer of hydrogen corresponds to about $210 \mu \mathrm{C} / \mathrm{cm}^{2}$ for real surface area. Figure 2 shows that the roughness factor is proportional to the charge that passed during Pt deposition. This result indicates that pores are open, and of the inner walls of pores are exposed, for the most parts, to the solution. Thus the pores act as electrochemically active surface. 


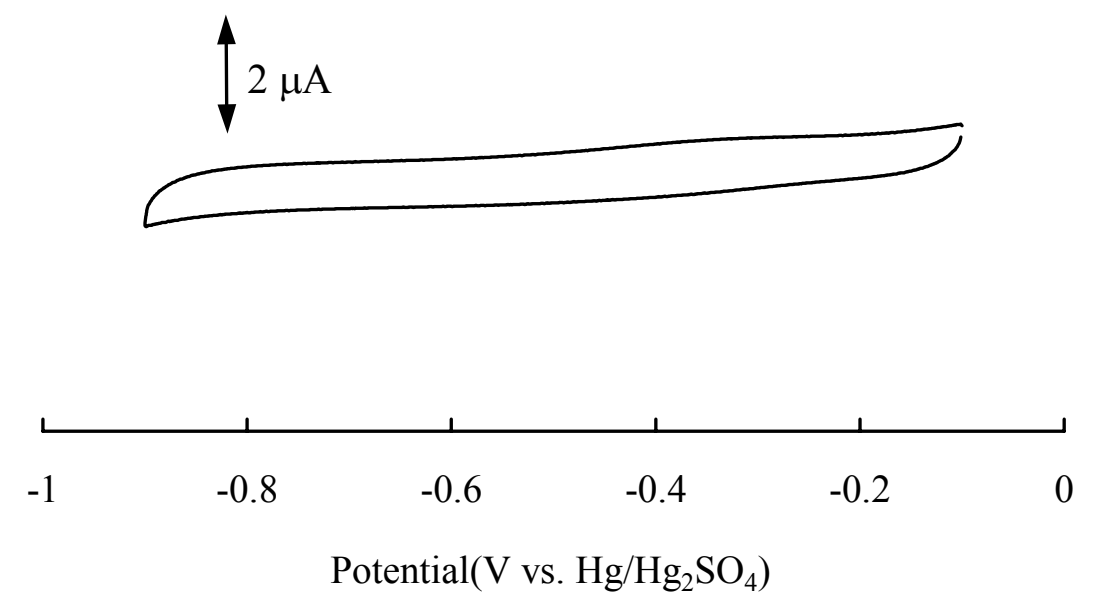

Figure 3. Cyclic voltammogram of Pt electrode in $0.1 \mathrm{M} \mathrm{NaF}$ aqueous solution.

Comment: The cyclic voltammogram of flat Pt electrode(radius $=1 \mathrm{~mm}$ ) was obtained in $0.1 \mathrm{M} \mathrm{NaF}$ solution showing the location of the electrical double layer region(no faradaic reaction), between $-0.9 \mathrm{~V}$ and $-0.1 \mathrm{~V}$ vs. $\mathrm{Hg} / \mathrm{Hg}_{2} \mathrm{SO}_{4}$. Thus differential capacitances were measured in the range from $-0.8 \mathrm{~V}$ to $-0.2 \mathrm{~V}$. 

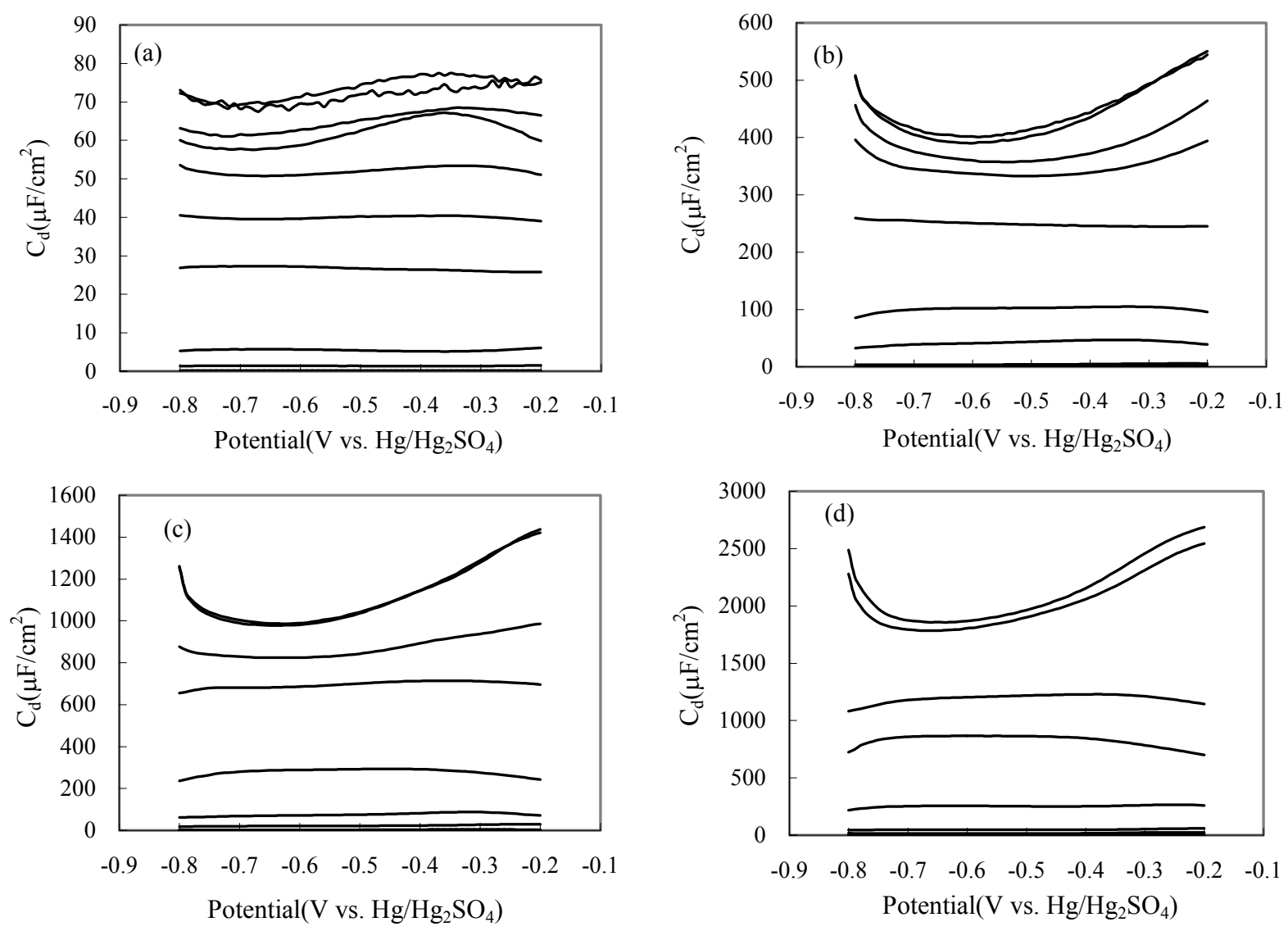

Figure 4. Differential capacitances of (a) flat(roughness factor, 2.37) and (b)-(d) mesoporous $\mathrm{Pt}$ electrodes in various electrolyte $(\mathrm{NaF})$ concentrations; from $0.1 \mathrm{mM}$ to 1 M. $\omega / 2 \pi=10 \mathrm{~Hz}$. The charge for Pt deposition and roughness factor of mesoporous $\mathrm{Pt}$ electrodes are (b) $5 \mathrm{mC}$ and 29.1, (c) $10 \mathrm{mC}$ and 65.1 (d) $25 \mathrm{mC}$ and 158, respectively.

Comment: It is well known in the literature that the differential capacitance is almost same as double layer capacitance(reference 10 in text) at low frequencies. In this study $10 \mathrm{~Hz}$ was selected as the frequency applied. In order to demonstrate the dependence of $C_{\mathrm{d}}$ on electrolyte concentration more clearly, Figure 1 in the text employed the $C_{\mathrm{d}}$ data at a specific potential, particularly at $-0.5 \mathrm{~V}$ vs. $\mathrm{Hg} / \mathrm{Hg}_{2} \mathrm{SO}_{4}$, which is close both to the previously estimated $E_{\mathrm{z}}$ for $\mathrm{Pt}$ (reference 9 in the text) and to the potential applied for $\mathrm{O}_{2}$ reduction in Figure 3. 

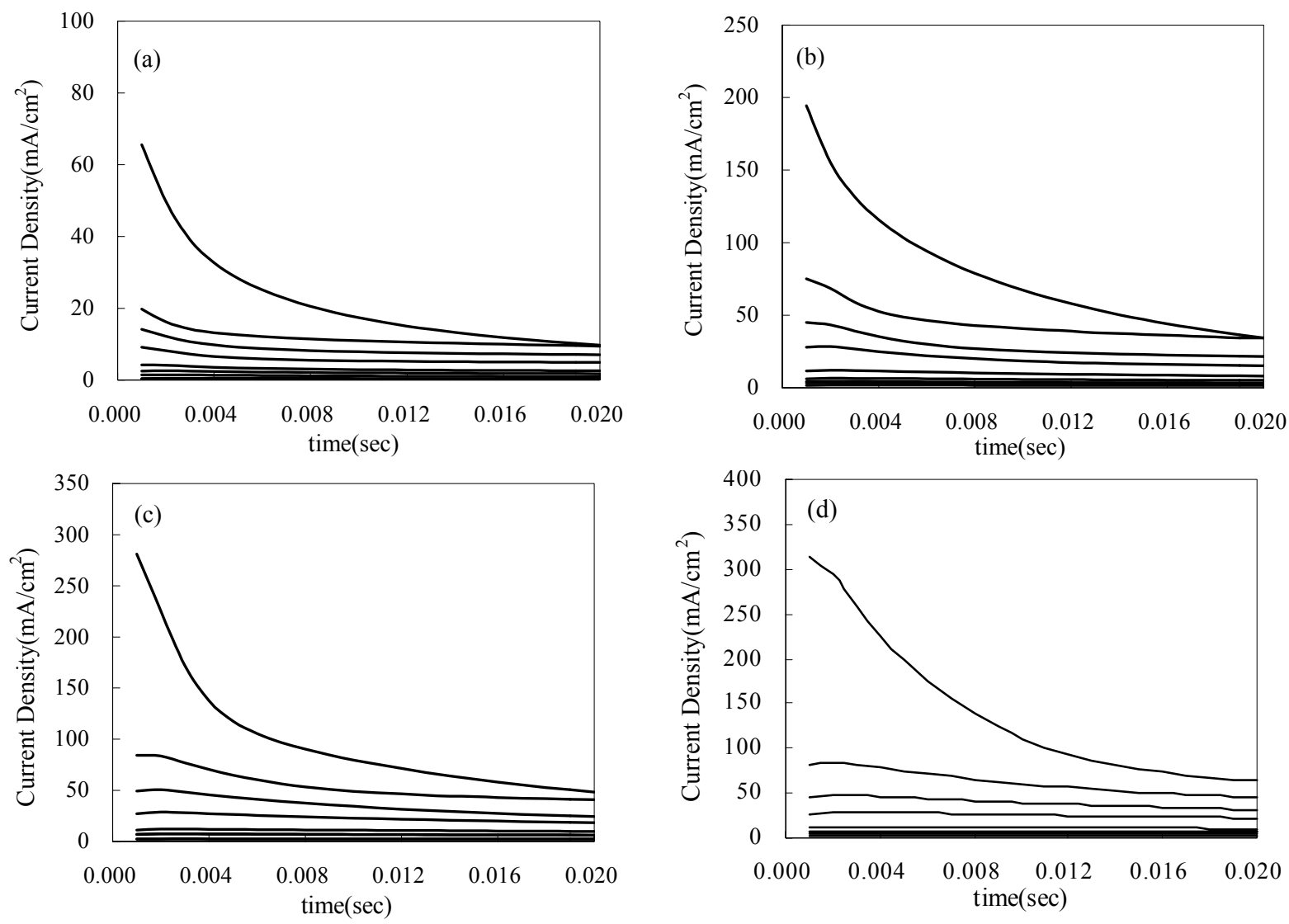

Figure 5. Chronoamperometry of $\mathrm{O}_{2}$ reduction at (a) flat Pt(roughness factor, 2.37) and (b)-(d) mesoporous Pt electrodes in various $\mathrm{NaF}$ concentrations; from $0.1 \mathrm{mM}$ to $1 \mathrm{M}$. Step potential is $-0.75 \mathrm{~V}$ vs. $\mathrm{Hg} / \mathrm{Hg}_{2} \mathrm{SO}_{4}$. The roughness factors of mesoporous $\mathrm{Pt}$ electrodes are (b) 29.1, (c) 65.1 and (d) 158.

Comment: The reduced form of $\mathrm{O}_{2}, \mathrm{O}_{2}{ }^{-}$radical, is not stable enough in aqueous solution. It was necessary to select the appropriate sampling time that does not only minimize interferences by possible side reactions but also avoid the effect of charging current. In this study it is estimated that the charging current decays to less than $0.05 \%$ in $10 \mathrm{msec}$. Thus the amperometric data were sampled $11 \mathrm{msec}$ after potential steps for all measurements. 